\title{
LV-OP-1-3
}

\section{Liver transplantation from discarded liver grafts: Expanding the donor liver pool in Mexico}

\author{
Carlos FLOREZ-ZORRILLA ${ }^{* 1}$, Karina MENDOZA-GALLO², Miguel CHARCO-CRUZ \\ 'HPB and Liver Transplantation, Centro Medico Nacional 20 de Noviembre-ISSSTE, Mexico City, Mexico \\ ${ }^{2}$ Department of Pediatrics, Hospital General Regional 46-IMSS, Guadalajara, Mexico
}

Introduction: Extended criteria donors (ECD) in liver transplantation has become a common policy because the shortage of optimal organs. Most of liver transplantation groups agree that prolonged cold ischemia, obesity, steatosis, age, hipernatremia, inotropic support, non heart beating donors (NHBD), split livers are related to primary non-function (PNF) of the liver graft with high morbidity and mortality. Discarded liver grafts by contrast accounts every year for more than two-fold the liver transplants done in Mexico. Poor donor characteristics such as steatosis $>40 \%$, severe hyponatremia, alcohol abuse and obesity are frequently cause of declination by most transplant teams.

Methods: A five year period was observed from January 2015 to January 2020. Donor variables such as severe hipernatremia $(>165$ Meq/l), moderate steatosis $(>40 \%)$, BMI $\left(>30 \mathrm{~kg} / \mathrm{m}^{2}\right)$, alcohol abuse and cold ischemia time (CIT) more than $8 \mathrm{hr}$ were recorded and considered risk factors for PNF. Delayed graft function (DGF), PNF and complications were evaluated. All liver donors were discarded by at least three main liver transplant centers in Mexico City.

Results: 155 LT were done. Marginal donors 60 (38.7\%). Discarded livers 40 (66.6\%). Severe hypernatremia (165-188 Meq/1), 19 (47.5\%), obesity $\left(30-45 \mathrm{~kg} / \mathrm{m}^{2}\right), 30(75 \%)$ and moderate to severe steatosis $(40-76 \%), 21(52.5 \%)$, alcohol abuse $2(5 \%)$. There were no differences in PNF rate, when three factors coexists DGF rate were slightly higher than control group. No differences in 1-year mortality.

Conclusions: Discarded livers are an acceptable choice to expand liver pool donors. Moderate steatosis, severe hypernatremia and obesity seems to be good candidates for LT. 